\title{
Sexual size dimorphism in ground squirrels (Rodentia: Sciuridae: Marmotini) does not correlate with body size and sociality
}

\author{
Jan Matějư ${ }^{1,2 \dagger}$ and Lukáš Kratochvíl $\left.\right|^{* \dagger}$
}

\begin{abstract}
Introduction: Sexual size dimorphism (SSD) is a widespread phenomenon in animals including mammals. It has been demonstrated that across species, the direction and magnitude of sexual dimorphism in body size often corresponds to social systems. Moreover, many animal lineages conform to "Rensch's rule", which states that male-biased SSD increases with body size. We tested whether considerable differences in sociality and large variation in body size were connected with the evolution of SSD in the structural body size of ground squirrels, an otherwise ecologically relatively homogenous group of terrestrial rodents.

Results: We found the general trend of male-biased SSD in ground squirrels, however, male size increases nearly perfectly isometrically with female size among species and sociality does not explain departures from this relationship. Species with different sociality grades significantly differ in body size, with the most social species tending to be the largest.

Conclusions: We suggest that lack of conformity with Rensch's rule in ground squirrels may be attributed to their low variation in SSD, and briefly discuss three potential causes of small magnitude of SSD in the structural size in rodents: low selection on SSD in structural dimensions, ontogenetic and genetic constraints and the existence of ecological/selection factors preventing the evolution of extensive SSD.
\end{abstract}

Keywords: Allometry, Constraints, Cynomys, Marmota, Phylogenetic comparative study, Social system, Spermophilus

\section{Introduction}

Sexual size dimorphism - a difference in size between males and females, is a widespread phenomenon in animals [1]; recently reviewed in [2]. The evolution of sexual size dimorphism (SSD) is usually ascribed to different selection pressures (natural or sexual selection) operating in males and females. Male-biased SSD is predominantly attributed to intense intrasexual competition in males [1,3], as is supported by the correlation between SSD and social or mating systems in several mammalian lineages, e.g. [4-6], as well as in mammals in general [3]. Nevertheless, the extent of SSD does not depend exclusively on male size, but it is a function of both male and female size and SSD often scales with body size. An allometric relationship between SSD and

\footnotetext{
* Correspondence: lukas.kratochvil@natur.cuni.cz

${ }^{\dagger}$ Equal contributors

'Departments of Zoology and Ecology, Faculty of Science, Charles University in Prague, Viničná 7128 44, Praha 2, Czech Republic

Full list of author information is available at the end of the article
}

body size has been documented in a wide array of animals at various taxonomical levels, and is described by the so-called "Rensch's rule". This empirical rule states that male-biased SSD tends to increase with increasing body size among related species [7]. Consequently, male size increases positively allometrically with female size and males are more evolutionary plastic in body size than females [2] and references therein, [8-10]. This rule holds across the whole mammalian clade, and is followed by some, but not all, mammalian orders [3].

Although male-biased SSD generally predominates among mammals, the review of sexual dimorphism among rodents indicates that monomorphism, male-biased and female-biased SSD is typical for particular rodent lineages [11]. It is of particular interest that rodents do not conform to Rensch's rule, although they possess a wide range of body sizes and extensive variability in social systems. The recent analysis was based on data covering nearly 300 species, and thus the lack of conformity with

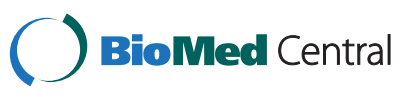


Rensch's rule could certainly not be attributed to small sample size [3]. However, it was speculated that these results may have been biased by the more extensive coverage of larger species in the dataset [3]. Moreover, the inclusion of species with different morphology, ecology and phylogenetic position into a single comparison may contribute to this pattern. Therefore, we decided to perform an analysis of SSD scaling on a new original dataset restricted to ground squirrels forming a rodent tribe that displays a wide range of body size and large diversity in social systems, yet are still similar in other aspects of their general biology.

Ground squirrels (tribe Marmotini Pocock, 1923; see [12]) are a monophyletic group within the family Sciuridae $[13,14]$. Ground squirrels occupy mostly open habitats of North America and Eurasia [15], are diurnal, omnivorous, reproduce usually once a year and all are semi-fossorial $[15,16]$. Members of the tribe display diverse social systems, from polygyny (a single male monopolizes multiple females), to promiscuity, where male success largely depends on scramble competition $[17,18]$. We can thus expect that the strength of sexual selection on male body size is different among particular species.

Specifically, we tested whether the allometry of SSD among ground squirrels corresponds to Rensch's rule and whether different levels of sociality, taken as a presumable correlate of the magnitude of sexual selection on male body size, correlates with SSD and the body size pattern.

\section{Results}

The two expressions of structural body size (condylo-basal length of the skull, CBL, and hind foot length, HFL) were highly correlated with each other across species (Pearson's product-moment correlation of species means, $r>0.975$, $\mathrm{p}<0.0001, \mathrm{n}=63$ for both males and females), but due to differences in body proportions among species, they exhibited somewhat different distributions (cf. Figure 1a, b). Although ground squirrels exhibit large variation in body size (Figure 1) and sociality, our comparison of male and female body size measurements revealed only limited variation in SSD. A significant presence of SSD among ground squirrels was found in $38 \%$ of included species based on CBL and in only $24 \%$ based on HFL (Table 1). Wherever significant, SSD proved to be male-biased, males being maximally around 8\% larger in CBL and 14\% larger in HFL. Estimations of SSD expressed as ratios of male to female mean CBL and HFL were correlated among species (Pearson's product-moment correlation, $\mathrm{r}=0.44, \mathrm{p}<0.001, \mathrm{n}=63$ ). Both these estimations do not significantly depart from normal distribution (Kolmogorov-Smirnov tests not significant) with means $1.026 \pm 0.003$ (S.E.) for CBL ratio and $1.037 \pm 0.005$ for HFL ratio. The linear regression of log-transformed species means of male CBL on log-transformed species means of
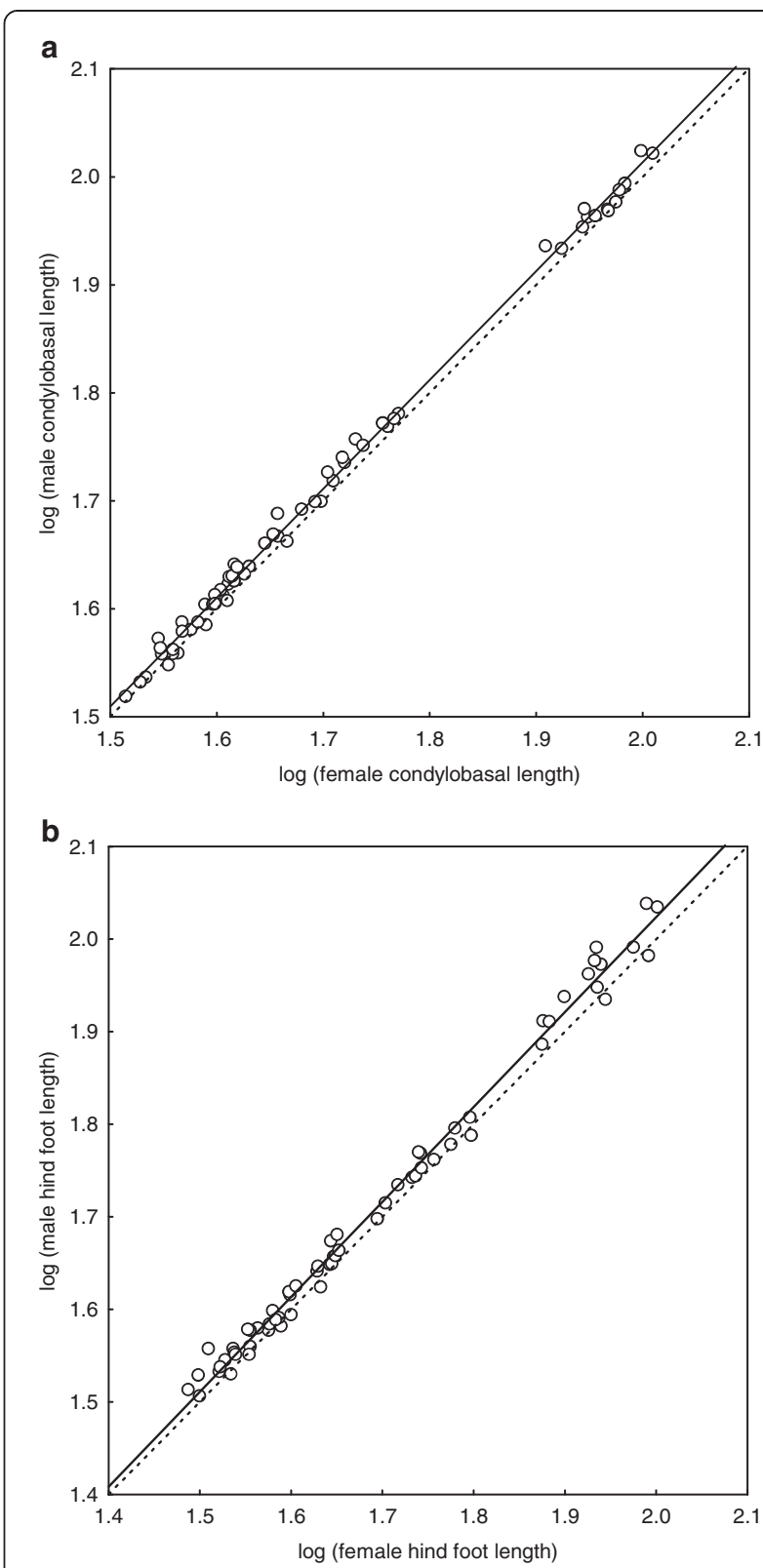

Figure 1 Mean male body size increases isometrically with mean female body size among species of ground squirrels. a) condylobasal length, b) hind foot length. Ordinary least-square regression (solid lines) and 1:1 relationship (dashed lines) are shown.

female CBL accounted for a large proportion of the variation $\left(\mathrm{r}^{2}=0.997, \mathrm{~F}=20296.75, \mathrm{p}<0.0001, \mathrm{n}=63\right)$ and showed a nearly perfectly isometric increase between male and female size across species (slope $1.008 \pm 0.007$ (means \pm S.E. are given), 95\%-CI 0.994-1.022; intercept n.s.; Figure 1a). Nearly identical results were found for log-transformed maximal CBL (proportion of explained variation by linear regression $\mathrm{r}^{2}=0.994, \mathrm{~F}=10241.77$, $\mathrm{p}<0.0001, \mathrm{n}=63$; slope $1.014 \pm 0.010,95 \%$-CI 0.994 1.034) and log-transformed mean HFL $\left(r^{2}=0.992, F=\right.$ 
Table 1 Sociality and body size, measured as hind foot length (HFL) and condylobasal length (CBL) in males and females of 63 species of ground squirrels and the tests of sexual size dimorphism within species

\begin{tabular}{|c|c|c|c|c|c|c|c|c|c|c|}
\hline \multirow[t]{2}{*}{ Species } & \multirow[t]{2}{*}{ Sociality } & \multicolumn{4}{|l|}{ HFL } & \multicolumn{4}{|l|}{ CBL } & \multirow{2}{*}{$\begin{array}{l}\text { References to } \\
\text { sociality grade }\end{array}$} \\
\hline & & $n(\mathrm{M}, \mathrm{F})$ & $\mathrm{M} / \mathrm{F}$ ratio & $\mathrm{F}$ & $p$ & $n(\mathrm{M}, \mathrm{F})$ & M/F ratio & $\mathrm{F}$ & $\mathrm{p}$ & \\
\hline Ammospermophilus harrisii & 1 & 6,6 & 1.044 & 2.500 & 0.145 & 6,6 & 0.990 & 0.678 & 0.429 & [19] \\
\hline Ammospermophilus insularis & 1 & 6,4 & 0.985 & 0.419 & 0.535 & 6,4 & 1.048 & 4.852 & 0.059 & {$[20]$} \\
\hline Ammospermophilus interpres & 1 & 6,6 & 1.007 & 0.117 & 0.740 & 6,6 & 1.000 & 0.002 & 0.969 & {$[21]$} \\
\hline Ammospermophilus leucurus & 1 & 6,6 & 1.020 & 0.636 & 0.444 & 6,6 & 1.023 & 2.183 & 0.170 & {$[22]$} \\
\hline Ammospermophilus nelsoni & & 6,6 & 1.042 & 4.032 & 0.072 & 6,6 & 1.012 & 1.556 & 0.241 & \\
\hline Callospermophilus lateralis & 1 & 15,15 & 0.982 & 1.013 & 0.323 & 15,15 & 0.995 & 0.251 & 0.620 & [18] \\
\hline Callospermophilus madrensis & 1 & 3,5 & 1.010 & 0.346 & 0.578 & 3,5 & 0.990 & 0.136 & 0.725 & {$[23]$} \\
\hline Callospermophilus saturatus & 1 & 15,15 & 1.027 & 3.944 & 0.057 & 15,15 & 1.037 & 11.526 & $0.002^{* *}$ & {$[23]$} \\
\hline Cynomys gunnisoni & 4 & 16,14 & 1.024 & 3.416 & 0.075 & 16,14 & 1.036 & 13.928 & $0.001^{* *}$ & [18] \\
\hline Cynomys leucurus & 2 & 14,15 & 1.011 & 0.118 & 0.734 & 15,15 & 1.038 & 22.521 & $<0.001^{* * *}$ & {$[18]$} \\
\hline Cynomys ludovicianus & 5 & 15,15 & 1.038 & 7.591 & $0.010^{*}$ & 15,15 & 1.024 & 7.640 & $0.010^{*}$ & [18] \\
\hline Cynomys mexicanus & 5 & 5,7 & 0.979 & 0.117 & 0.740 & 5,7 & 1.020 & 2.591 & 0.139 & {$[24]$} \\
\hline Cynomys parvidens & 4 & 15,10 & 1.064 & 4.136 & 0.054 & 15,10 & 1.064 & 44.093 & $<0.001^{* * *}$ & {$[25,26]$} \\
\hline Ictidomys mexicanus & & 9,11 & 1.041 & 2.958 & 0.103 & 9,11 & 1.012 & 0.203 & 0.658 & \\
\hline Ictidomys parvidens & & 7,7 & 1.048 & 2.101 & 0.173 & 7,7 & 1.036 & 5.986 & $0.031^{*}$ & \\
\hline Ictidomys tridecemlineatus & 2 & 15,15 & 1.055 & 9.068 & $0.005^{* *}$ & 15,15 & 1.013 & 1.074 & 0.309 & {$[18]$} \\
\hline Marmota baibacina & 5 & 9,4 & 1.089 & 2.595 & 0.136 & 10,5 & 1.020 & 0.691 & 0.421 & {$[27]$} \\
\hline Marmota bobac & 5 & 15,9 & 1.093 & 15.947 & $0.001^{* *}$ & 15,11 & 1.033 & 4.604 & $0.042^{*}$ & {$[27]$} \\
\hline Marmota broweri & 5 & 1,2 & 1.080 & 16.333 & 0.154 & 5,6 & 1.020 & 0.557 & 0.475 & {$[27]$} \\
\hline Marmota caligata & 5 & 14,14 & 1.039 & 3.032 & 0.093 & 15,15 & 1.024 & 2.168 & 0.152 & {$[27]$} \\
\hline Marmota camtschatica & 5 & 7,9 & 1.084 & 5.059 & $0.041^{*}$ & 15,17 & 1.024 & 2.018 & 0.166 & {$[27]$} \\
\hline Marmota caudata & 5 & 12,8 & 0.978 & 4.136 & 0.054 & 15,15 & 1.023 & 0.974 & 0.332 & {$[27]$} \\
\hline Marmota flaviventris & 4 & 22,23 & 1.066 & 10.125 & $0.003^{* *}$ & 24,24 & 1.065 & 21.606 & $<0.001^{* * *}$ & {$[17]$} \\
\hline Marmota himalayana & 5 & 4,3 & 1.140 & 5.560 & 0.065 & 14,10 & 1.029 & 2.236 & 0.149 & {$[27]$} \\
\hline Marmota marmota & 5 & 12,6 & 0.978 & 0.644 & 0.434 & 17,10 & 1.007 & 0.240 & 0.628 & {$[27]$} \\
\hline Marmota menzbieri & 5 & 1,2 & 1.028 & 0.870 & 0.522 & 3,3 & 1.023 & 2.638 & 0.180 & {$[27]$} \\
\hline Marmota monax & 1 & 15,15 & 1.029 & 1.551 & 0.223 & 15,15 & 1.004 & 0.091 & 0.765 & {$[17,27]$} \\
\hline Marmota olympus & 5 & 3,5 & 1.120 & 4.903 & 0.069 & 7,6 & 1.061 & 14.770 & $0.003^{* *}$ & {$[17,18,27]$} \\
\hline Marmota sibirica & 5 & 5,5 & 1.107 & 3.974 & 0.081 & 16,16 & 1.060 & 18.914 & $<0.001^{* * *}$ & {$[27]$} \\
\hline Marmota vancouverensis & 5 & 3,4 & 1.081 & 0.358 & 0.576 & 5,4 & 1.002 & 0.008 & 0.931 & {$[27]$} \\
\hline Notocitellus adocetus & & 9,7 & 1.026 & 1.553 & 0.233 & 9,7 & 1.014 & 0.581 & 0.459 & \\
\hline Notocitellus annulatus & & 14,13 & 1.018 & 4.136 & 0.054 & 14,13 & 1.004 & 0.091 & 0.766 & \\
\hline Otospermophilus beecheyi & 2 & 15,15 & 1.074 & 17.659 & $<0.001^{* * *}$ & 15,15 & 1.064 & 12.426 & $0.001^{*}$ & {$[17]$} \\
\hline Otospermophilus atricapillus & & 8,10 & 1.028 & 1.897 & 0.187 & 8,10 & 1.021 & 1.021 & 0.327 & \\
\hline Otospermophilus variegatus & 3 & 14,15 & 1.028 & 2.446 & 0.129 & 14,15 & 1.022 & 3.951 & 0.057 & {$[28]$} \\
\hline Poliocitellus franklinii & 1 & 15,15 & 1.056 & 7.736 & $0.010^{*}$ & 15,15 & 1.016 & 2.081 & 0.160 & {$[18]$} \\
\hline Spermophilus alashanicus & & 1,5 & 1.038 & 0.340 & 0.591 & 2,5 & 1.059 & 3.545 & 0.118 & \\
\hline Spermophilus citellus & 2 & 15,15 & 1.010 & 0.126 & 0.725 & 17,16 & 1.028 & 3.492 & 0.071 & J. Matějů, own data \\
\hline Spermophilus dauricus & & 16,15 & 1.051 & 5.067 & $0.032^{*}$ & 16,15 & 1.022 & 2.421 & 0.131 & \\
\hline Spermophilus erythrogenys & & 15,15 & 1.044 & 5.067 & $0.032^{*}$ & 16,15 & 1.073 & 32.773 & $<0.001^{* * *}$ & \\
\hline Spermophilus fulvus & 3 & 5,9 & 1.029 & 0.336 & 0.573 & 17,15 & 1.032 & 5.431 & $0.027^{*}$ & {$[29,30]$} \\
\hline Spermophilus major & & 15,16 & 1.073 & 4.785 & $0.037^{*}$ & 15,16 & 1.053 & 9.868 & $0.004^{* *}$ & \\
\hline
\end{tabular}


Table 1 Sociality and body size, measured as hind foot length (HFL) and condylobasal length (CBL) in males and females of $\mathbf{6 3}$ species of ground squirrels and the tests of sexual size dimorphism within species (Continued)

\begin{tabular}{|c|c|c|c|c|c|c|c|c|c|c|}
\hline Spermophilus musicus & & 16,14 & 1.045 & 2.729 & 0.110 & 16,15 & 1.042 & 9.784 & $0.004^{* *}$ & \\
\hline Spermophilus pygmaeus & 2 & 16,15 & 1.073 & 12.634 & $0.001^{* *}$ & 16,15 & 1.035 & 8.442 & $0.007^{* *}$ & $\begin{array}{l}\text { [31], A.V. Tchabovsky } \\
\text { pers. comm }\end{array}$ \\
\hline Spermophilus relictus & & 6,13 & 0.982 & 0.273 & 0.608 & 6,13 & 0.995 & 0.052 & 0.822 & \\
\hline Spermophilus suslicus & 2 & 16,15 & 1.060 & 7.928 & $0.009^{* *}$ & 16,15 & 1.015 & 0.661 & 0.423 & $\begin{array}{l}\text { A.V. Tchabovsky } \\
\text { pers. comm. }\end{array}$ \\
\hline Spermophilus xanthoprymnus & 2 & 11,11 & 1.061 & 3.615 & 0.072 & 11,11 & 1.046 & 5.715 & $0.027^{*}$ & $\begin{array}{l}{[32,33], \text { V. Vohralík }} \\
\text { pers. comm. }\end{array}$ \\
\hline Urocitellus washingtoni & & 15,15 & 1.038 & 4.395 & $0.045^{*}$ & 15,15 & 1.039 & 13.177 & $0.001^{* *}$ & \\
\hline Urocitellus armatus & 2 & 15,15 & 1.014 & 1.101 & 0.303 & 15,15 & 1.021 & 1.868 & 0.183 & [18] \\
\hline Urocitellus beldingi & 2 & 15,15 & 1.011 & 0.527 & 0.474 & 15,15 & 1.015 & 2.501 & 0.125 & [18] \\
\hline Urocitellus brunneus & & 7,3 & 1.044 & 1.434 & 0.265 & 7,3 & 1.065 & 11.068 & $0.010^{*}$ & \\
\hline Urocitellus cannus & 2 & 15,15 & 1.015 & 0.429 & 0.518 & 15,15 & 1.011 & 0.794 & 0.381 & {$[17,18]$} \\
\hline Urocitellus columbianus & 3 & 15,15 & 1.008 & 0.208 & 0.652 & 15,15 & 1.029 & 3.526 & 0.071 & [18] \\
\hline Urocitellus elegans & 2 & 15,15 & 1.029 & 2.454 & 0.128 & 15,15 & 1.033 & 7.597 & $0.010^{*}$ & [18] \\
\hline Urocitellus mollis & 2 & 15,15 & 1.028 & 1.620 & 0.214 & 15,15 & 1.008 & 0.304 & 0.586 & {$[17,18]$} \\
\hline Urocitellus parryii & 3 & 15,15 & 1.000 & 0.000 & 1.000 & 15,15 & 1.037 & 14.354 & $0.001^{* *}$ & [18] \\
\hline Urocitellus richardsonii & 2 & 15,15 & 1.073 & 20.956 & $<0.001^{* * *}$ & 15,15 & 1.036 & 7.284 & $0.012^{*}$ & [18] \\
\hline Urocitellus townsendii & 2 & 15,12 & 0.993 & 0.629 & 0.472 & 15,12 & 0.986 & 1.658 & 0.210 & {$[17,18]$} \\
\hline Urocitellus undulatus & & 15,18 & 1.040 & 5.592 & $0.024^{*}$ & 15,18 & 1.038 & 13.657 & $0.001^{* *}$ & \\
\hline Xerospermophilus mohavensis & 1 & 4,2 & 1.036 & 0.629 & 0.472 & 5,6 & 1.008 & 0.757 & 0.407 & [34] \\
\hline Xerospermophilus perotensis & & 8,5 & 1.012 & 0.939 & 0.353 & 8,5 & 1.019 & 3.831 & 0.076 & \\
\hline Xerospermophilus spilosoma & & 15,15 & 1.030 & 3.811 & 0.061 & 15,15 & 1.027 & 6.995 & $0.013^{*}$ & \\
\hline Xerospermophilus tereticaudus & 2 & 15,15 & 0.995 & 0.137 & 0.714 & 16,18 & 1.009 & 1.316 & 0.260 & [18] \\
\hline
\end{tabular}

${ }^{*} \mathrm{p}<0.05,{ }^{* *} \mathrm{p}<0.01,{ }^{* * *} \mathrm{p}<0.001$.

7268.03, $\mathrm{p}<0.0001, \mathrm{n}=63$; slope $1.026 \pm 0.012,95 \%$-CI 0.999 - 1.050; Figure 1b). In the case of log-transformed maximal HFL, linear regression $\left(\mathrm{r}^{2}=0.986, \mathrm{~F}=2105.32\right.$, $\mathrm{p}<0.0001, \mathrm{n}=63)$ revealed a slight but significant departure from isometry (slope $1.058 \pm 0.023$ (S.E.), $95 \%$-CI 1.012 - 1.105) caused by the single influential outlier, Marmota vancouverensis, one of the largest species. The high value of maximal HFL for males of this species was caused by a single individual with unusually long feet. We suggest that mean species values are less sensitive to such outlying individuals with extreme measurements, and we use them henceforth as more reliable expressions of size.

Sociality does not significantly explain departures of mean male CBL from the common relationship with mean female CBL across species, and generally explains only a minor proportion of the total variability (ANCOVA: mean male CBL as continuous dependent variable; mean female CBL as a continuous independent variable: $\mathrm{F}_{1,40}=5304.68$, $\mathrm{p}<0.0001$, sociality coded as five grades as categorical independent variable: $\mathrm{F}_{4,40}=2.05, \mathrm{p}=0.11$ ). The results of the ANCOVA model for mean HFL as a proxy of body size were congruent with this conclusion (mean male HFL as dependent continuous variable, mean female HFL: $\mathrm{F}_{1,40}=828.28, \mathrm{p}<0.0001$, sociality: $\mathrm{F}_{4,40}=0.37, \mathrm{p}=0.83$ ).

Nevertheless, species with different sociality grades significantly differ in body size, with the most social species tending to be the largest (one-way ANOVA of mean male CBL, factor sociality: $\mathrm{F}_{4,41}=29.03$, $\mathrm{p}<0.0001$; Figure 2; the results for female mean CBL and male and female mean HFL are practically identical). The results do not differ when sociality is coded as $0-1$ dummy variable (not shown).

Phylogenetically-informed analyses confirmed that the results and their interpretations cannot be explained by a bias caused by shared ancestry. Pagel's $\lambda$ estimated in the phylogenetic generalized least squares (PGLS) regression of log-transformed mean male CBL on log-transformed mean female CBL is very low (0.07) and close to 0.0 , which indicates that the effect of phylogeny on the allometry of SSD expressed in CBL is minimal. This conclusion is supported by the result of the likelihood ratio (LR) test showing that the PGLS models with $\lambda$ restricted to 0.0 (equivalent to the ordinary least squares regression based on raw data) and 


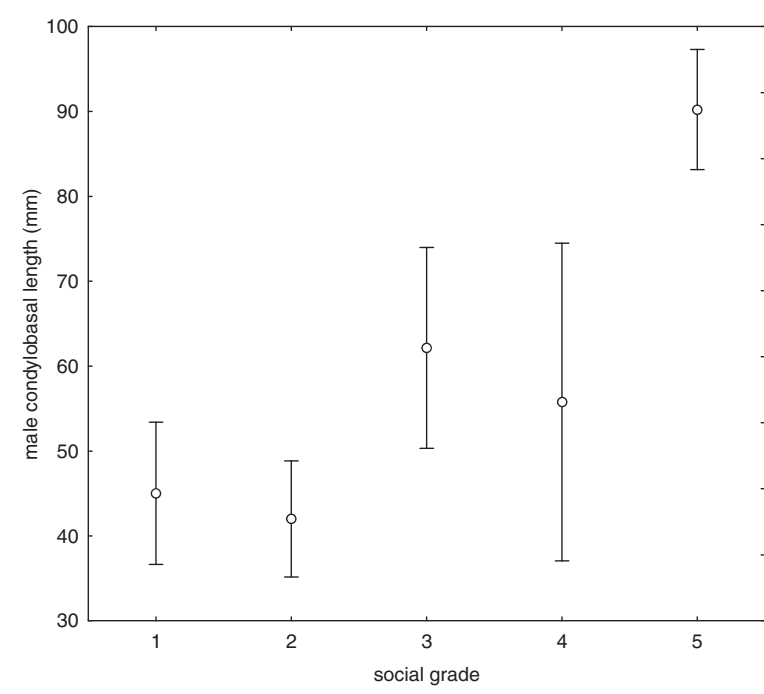

Figure 2 Body size tends to increase with sociality among species of ground squirrels. Results of one-way ANOVA of male condylobasal length results are shown as means and 95-\% confidence intervals.

with $\lambda=0.07$ are statistically indistinguishable $\left(\mathrm{LR}_{1}=0.32\right.$, $\mathrm{p}=0.57)$. The analyses of independent contrasts, although not supported by the PGLS regression as adequate, also support the isometric increase of log-transformed male CBL with log-transformed mean female CBL (not shown). On the other hand, the effect of phylogeny is significant in the allometry of SSD based on HFL measurements, where $\lambda$ estimated by maximum likelihood in the PGLS model is 0.67 . The LH test confirmed significant differences between the fits of the PGLS models with $\lambda=0.67$ and $\lambda=0.0$ $\left(\mathrm{LR}_{1}=4.06, \mathrm{p}=0.044\right)$. The fits of the PGLS models with $\lambda=0.67$ and $\lambda=1.0$, equivalent to phylogenetic independent contrasts, are not statistically different $\left(\mathrm{LR}_{1}=1.68, \mathrm{p}=0.19\right)$. Independent contrasts in logtransformed mean male HFL and log-transformed mean female HFL scales isometrically $\left(\mathrm{r}^{2}=0.960\right.$, slope $0.965 \pm 0.050$ is not different from 1.0 expected under isometry, $\mathrm{n}=62$ contrasts), which proves isometric scaling of male and female size in HFL as well.

Comparisons of the fits of the nested PGLS models with and without sociality as a predictor confirmed that addition of sociality into the models does not increase their explanatory power. The fit of the multivariate PGLS model of log-transformed mean male CBL on logtransformed mean female CBL and sociality coded as the five grades is not statistically different from the model after dropping of the predictor sociality $\left(\mathrm{LH}_{1}=0.44, \mathrm{p}=0.51\right)$. The same is true for sociality coded as the 0 -1dummy variable $\left(\mathrm{LH}_{1}=1.44, \mathrm{p}=0.23\right)$. The situation for the models based on log-transformed HFL measurements is equivalent (sociality coded as five grades: $\mathrm{LH}_{1}=0.14, \mathrm{p}=0.71$; sociality coded as $0-1: \mathrm{LH}_{1}=0.02 \mathrm{p}=0.89$ ). Non-significance of the factor sociality was found also in the multiple regression of independent contrasts (not shown). Estimates of Pagel's $\lambda$ were large (between 0.78 and 1.0) in all PGLS models describing association of log-transformed CBL and HFL with sociality coded either as five grades or a 0-1 dummy variable for males and females, respectively, showing a significant influence of phylogenetic relationships on the correlation between body size and sociality. The LH tests confirmed that these PGLS models are not significantly different from the respective models with $\lambda$ restricted to 1.0 equivalent to phylogenetic independent contrasts (all p > 0.15). The analyses of phylogenetic contrasts confirmed significant correlations between log-transformed mean CBL and mean HFL in males and females and sociality coded as five grades and $0-1$, respectively (all $\mathrm{r}>0.39, \mathrm{p}<0.05, \mathrm{n}=45$ contrasts).

Exclusion of seven species (Ammospermophilus insularis, Callospermophilus madrensis, Marmota menzbieri, Marmota vancouverensis, Urocitellus brunneus and Spermophilus alashanicus) with sample size less than five individuals for at least one sex in CBL does not change significance of any results and the major interpretations are thus robust with respect to inclusion of these species with small sample size.

\section{Discussion}

Our results revealed only limited variation in SSD in two measurements representing different aspects of structural body size among ground squirrels, although we stress that the lack of significant SSD in some species can be attributed to small sample size. This variability in SSD cannot be explained by either of the two commonly reported correlates of SSD, i.e. body size and social system. Ground squirrels thus do not conform to Rensch's rule, in contrast to the general trend in mammals [3]. Our results, based on an original morphometric dataset covering most species in a monophyletic group with similar general biology, are thus in line with a previous report showing similar results in rodents [3]. Rensch's rule is usually not followed in groups with female-biased SSD [35-37]. Here, we report that it is not followed in a mammalian group with predominantly male-biased SSD.

We suggest that the limited extent of SSD in structural body size and the lack of the support for Rensch's rule in ground squirrels could be generally explained by three possible scenarios: i) low selection on SSD in structural dimensions, ii) ontogenetic and genetic constraints or iii) the existence of ecological/selection factors preventing the evolution of extensive SSD.

Male-biased SSD, typical for mammals, is usually associated with sexual selection on body size enlargement that correlates with success in female monopolization. Reiss [38] argued that the relationship between body size and SSD found in some mammalian lineages can be largely 
explained by the co-variation of mating systems with body size: larger species have a larger opportunity for polygyny and thus stronger selection for male size increases leading to male-biased SSD. The pattern consistent with Rensch's rule driven probably by sexual selection in males has also been found in other animal groups, i.e. shorebirds [39]. In ground squirrels, social organization changes with body size. Small species are typically less social and hence presumably more promiscuous [18], while the more social larger species probably exhibit larger selective pressure on female monopolization and hence body size enlargement in males. This is also evident in marmots, the largest species of ground squirrels, where polygyny or facultative monogamy is based on active female-defence [18]. A correspondence between social grade and sexual selection on male size enlargement in ground squirrels is supported by single-species studies. For instance, success in male-male combat over females is positively related to male body size in Urocitellus parryii [40], where territorial males are associated with female kin clusters (social grade 3; [18]). Similarly, larger males of most Cynomys species (grades 3-5) are more successful in securing breeding territories and sire more offspring [41]. On the other hand, selection pressure towards smaller male body size was observed in the low social (grade 2) promiscuous Ictidomys tridecemlineatus, where males are selected for maneuverability and early sexual maturation [42].

In summary, selection for male body size enlargement should increase with increased sociality and body size in ground squirrels, which should lead to a pattern consistent with Rench's rule. We can thus tentatively conclude that differences in sexual selection among ground squirrels, although associated with body size variation, do not lead to conformity with Rensch's rule. The support for Rensch's rule across breeds of domestic mammals suggests that the allometry for SSD could be a more general consequence of body size evolution caused by different selective agents $[43,44]$. Nevertheless, ground squirrels do not follow the rule although they have large variation in body size. We suggest that this state can be explained by the limited extent of SSD in this rodent group.

Limited SSD could reflect ontogenetic or genetic constraints, an idea going back to Charles R. Darwin [1], see also e.g. [45,46]. It is notable that a generally low degree of SSD in structural body size has been reported for rodents [11], although they inhabit a wide variety of habitats and possess various social systems. Nevertheless, it is not clear why rodents should have, for instance, a stronger intersexual genetic correlation in body size than other animal groups. Moreover, the existence of SSD (although with limited magnitude) in some species of ground squirrels suggest that there is sufficient genetic variation for SSD and that this trait should thus be subject to evolution.
Alternatively, selection may operate on male and female structural size independently, males being shaped by sexual selection and females by fecundity selection, but the optimal size for both sexes can be similar. In most ground squirrel species, female reproductive success (litter size, progeny survival) is positively related to body size [41,47-49]. Selection pressure towards larger female body size may contribute to low SSD in ground squirrels; however, it is not clear why male and females of species differing in body size and thus the energetics of growth and reproduction, and also having different mating or social systems, should always have a similar optimal body size.

It is also possible that there is selection for an increase of SSD in structural size, but that this pressure is counterbalanced by other selective pressures constraining its extent and resulting in both sexes having a similar, optimal structural body size. One potential limiting factor for large differences in such SSD is the subterranean environment. Both male and female ground squirrels occupy underground burrows, which they often share for mating, shelter e.g. $[50,51]$ and even hibernation in some marmot species $[16,50]$. The disadvantage of significant male and female body size differences in this case is apparent - large animals can suffer locomotion difficulties in tunnels made by smaller individuals. This hypothesis makes a straightforward prediction that SSD should be larger in species where both sexes do not share common underground tunnels, which could be tested in future comparative analyses.

It is necessary to stress that the limited extent of SSD in ground squirrels may only be restricted to structural size measurements. Sexual differences in ground squirrel body mass are often more pronounced (for reviews see [11,52]). For example, seasonally variable sexual body mass dimorphism was found in Utah prairie dogs (Cynomys parvidens) where the M:F ratio varies across seasons between 0.99 and even 1.53 [41]. Part of this large range in body mass SSD can be attributed to the fact that body mass increases approximately with the third power of length measurements. Nevertheless, the SSD index for mean CBL in this species is only around 1.06, which predicts that males should be only $20 \%$ heavier than females. It is evident that SSD in body mass reflects not only differences in structural body size, but also different allocations of males and females to fat reserves or musculature and different energetic consequences of reproduction.

Although SSD in structural body size is not associated with body size and sociality, sociality and body size proved to be highly correlated (Figure 2). Solitary and gregarious species (grades 1 and 2) tend to be small, while especially polygynous and/or monogamous species living in stable family groups (grade 5) are large. The ultimate explanations of the evolution of social living in ground 
squirrels may be anti-predator behaviour and the male protection of offspring against infanticide [18]. Correlation between sociality and body size in ground squirrels can be proximately explained by longer postnatal growth and development in large species, which leads to the longer retention of offspring within the maternal home range [17] and a large coincidence of above-ground activity between adult and immature cohorts [18], hence allowing a longer time for the building of social contacts.

\section{Conclusions}

The analyses of our original dataset confirmed low SSD in the structural dimensions of ground squirrels, a group with variable social systems and large variation in body size. We also found that male and female body structural sizes increase nearly perfectly isometrically, and that the group does not follow the otherwise widely applicable Rensch's rule. Negative results are more difficult to explain than positive findings; however, we suggest that the lack of conformity with Rensch's rule in ground squirrels may be attributed to the generally low variation of SSD in structural size in rodents, a phenomenon that deserves further comparative work.

\section{Material and methods}

We measured CBL in 1527 specimens from museum collections. Our material covers 63 out of 68 species of ground squirrels recently recognized in the tribe Marmotini sensu [12]; for the number of species see [53]. Only adult, undamaged and located specimens (modus 15 per sex-species category) were examined. Adults were identified according to the degree of teeth abrasion or stage (adult/juvenile) was obtained directly from specimen tags. Our dataset can be biased by geographic intraspecific variability in body size documented in ground squirrels [54]. Nevertheless, taking into account the large variability in body size across species of the studied group, we expect that intraspecific variability does not largely influence the interspecific pattern. Moreover, only individuals determined as a same subspecies and/or collected within a restricted geographic area were measured in most species. Four Spermophilus species (S. ralli, S. pallidicauda, S. taurensis and S. brevicauda) and Marmota kastschenkoi were not included into our study, as we were not able to obtain enough specimens. All CBL measurements were taken by a single person (JM). Data on HFL for adult males and females of each species were taken from museum tags (in total available in 1392 specimens, Table 1).

Body mass is often used as a measure of body size in the SSD literature, including [3]. Nevertheless, body mass is not a good expression of body size in ground squirrels [54], because many species considerably fluctuate in body mass throughout the year. For instance, data on body mass before and after hibernation are highly different e.g. [55] and are not comparable to body mass in less seasonal species. Our measurements, CBL and HFL, represent the structural component of size that is less dependent on body conditions. Moreover, it is known that HFL in rodents is among those external measurements that reach their final size very early during postnatal ontogeny e.g. [56,57]. There is not a single perfect measurement expressing general body size (see e.g. [58]) and most body measurements use to be highly intercorrelated in morphometric analyses. For example, skull measurements are highly correlated with each other in ground squirrels [54]. To avoid this problem, we selected CBL and HFL, because they reflect size of very different body parts, although due to large variability in body size among ground squirrels, we can $a$ priori expect that these measures will be highly correlated across all species included (we tested the correlation by Pearson test for males and females separately).

The data on social organization were obtained in two ways. Most of information was taken from literature concerning ground squirrel sociality $[17,18,27]$. Second, the level of sociality was classified using publications on general biology (see Table 1 for particular references) or our personal knowledge of the species biology (S. citellus). In this way, sociality was particularly assessed for the genus Ammospermophilus, species Callospermophilus madrensis, C. saturatus, Cynomys mexicanus, C. parvidens, Otospermophilus variegatus, Spermophilus citellus, S. suslicus, S. pygmaeus, S. fulvus, S. xanthoprymnus and Xerospermophilus mohavensis. Moreover, in the case of mentioned Palaearctic species, the social grades assignment was consulted with A. V. Tchabovski (N. A. Severtsov Institute of Ecology and Evolution, Russian Academy of Sciences) and V. Vohralík (Faculty of Science, Charles University in Prague). In classifying the species social grades, we especially consider descriptions of interindividual contacts, age of first reproduction, age of dispersal, character of dispersal and density of individuals (see [17] documenting correlation of sociality and the mentioned variables).

Species were classified into five categories representing different levels of sociality defined by [18]: 1 - asocial, 2 - single-family female kin clusters, 3 - female kin clusters with a territorial male, 4 - polygynous harems with male dominance, 5 - egalitarian polygynous harems. Facultative monogamy, known in some marmots, was included in the last category, as it is usually interpreted as an extreme case of polygyny where males are unable to monopolize more than one female under harsh environmental conditions ([59] and references therein). In cases of transient classification (i.e. level $1-2$ in Urocitellus townsendii, Ictidomys tridecemlineatus, and $2-3$ in Otospermophilus beecheyii) of species sociality in [18], we adopted the social grades of [17]. Despite extensive literature search we were not able to obtain or estimate data 
about sociality in 17 species from our morphological dataset. These species are thus not included into the analyses concerning effects of sociality. The sociality scale in ground squirrels forms a continuum from the least social (grade 1) to the most social (grade 5) organization; species placed into same category have similar but not always identical social system [18]. Throughout this work, we assume that these social grades reflect the strength of sexual selection on males. However, we are aware that social systems are not always necessary surrogates for mating systems, e.g. [60]. We summarized information about species mating systems as well, but primary data for the group are scarce and frequently in contradiction, for a review see [59]. Moreover, the definition of the polygynous mating system is disputable in rodents [59].

The significance of SSD in a given species was tested by one-way ANOVAs. We expressed SSD as ratios of male to female mean CBL and HFL and tested whether the SSD estimation from CBL and HFL are correlated across species by Pearson's product-moment correlation. We also tested whether these SSD indexes follow normal distribution across species by Kolmogorov-Smirnov test. Ordinary least square regression of log-transformed mean or maximal size measurements in males on logtransformed mean or maximal size measurements in females was used for testing the allometry of SSD and hence Rensch's rule. Slope 1.0 was expected under isometric increase of male size with female size. The ANCOVA models with size measurements in males as the dependent continuous variable, size measurements in females as the continuous independent variable and degree of sociality as the independent categorical variable were used to test the relationship between SSD and sociality among species. We tested the effect of sociality on species body size by one-way ANOVAs with male, respectively female body size measurements as dependent variable and sociality as factor.

Because species data are not independent, we performed analyses that take the phylogenetic relationship among species into account as well, specifically, the analyses of phylogenetic independent contrasts and PGLS [61-63]. We used the topology of the tribe published recently by [14]. Three species (U. cannus, $U$. mollis and A. nelsoni) are missing in their tree. We took the position of $U$. cannus and $U$. mollis from [13]. A. nelsoni is considered to diverged from $A$. leucurus, following [64], we took it as sister to this species. See the Additional file 1 for the whole composite tree. The branch length estimations for our tree are not available. Nevertheless, simulated studies showed that the independent contrasts method is sufficiently robust to errors in branch lengths [65]. We report results based on arbitrary, equal branch length both in PGLS models and in analyses of phylogenetic independent contrasts. In some cases, the phylogenetic contrasts based on equal branch length did not meet assumptions suggested by [66]. Therefore, in the analyses of independent contrasts, we used Graafen's branch lengths instead as well, which did not lead to significant correlations between contrasts and branch length [66]. The results of all analyses of phylogenetic independent contrasts computed using either equal or Graafen's branch lengths were equivalent; therefore, we report only the results for equal branch length.

We used phylogenetic independent contrasts [62] and PGLS models $[63,67]$ - for recent application, discussion and minute description of the PGLS technique see e.g. $[68,69]$ - to test for allometry in SSD, association of SSD with sociality and correlation between body size and sociality. In PGLS, the $\lambda$ parameter is found by maximum likelihood. This parameter potentially varies between 0 , indicating no effect of phylogenetic signal, and 1, corresponding to the analysis of independent contrasts where trait variation among species is predicted by phylogeny. Fit of nested PGLS models (models with and without a particular predictor) or PGLS models with and without a parameter restricted to a constant (e.g. $\lambda$ can be restricted to 0 or 1 , estimation of the $\lambda$ parameter requires 1 degree of freedom) can be compared using a LR test: $L_{d f}=-2 \times$ [Lh (better-fitting model) - Lh (worse-fitting model)], where the best fitting model has the highest log-likelihood (Lh) score. The significance of this difference can be evaluated with a $\chi^{2}$ distribution with degrees of freedom equal to the difference in the number of parameters between the two competing models [63]. We used this approach for comparison of PGLS models with $\lambda$ estimated by maximum likelihood with the analyses of raw data $(\lambda$ restricted to 0 in PGLS) or of independent contrasts ( $\lambda$ restricted to 1$)$ to estimate the impact of the phylogenetic signal for a given analysis. Further, we applied this procedure for comparison of PGLS models with and without predictor sociality to test the association of sociality on SSD.

Degree of sociality is an ordered variable. In many cases, an ordered variable represent coarse information about an underlying continuous variable, which is also true in our case [18]. Thus, we used it in PGLS regressions and analysis of independent contrasts as a continuous variable. This approach may lead to increased Type I error largely due to potentially unequal distances between subsequent categories [70]. To control for this potential bias, we also coded sociality as a variable with two levels, that can be used as a dummy variable in regressions. In this approach, we coded sociality grades 1 and 2 as 0 , and the grades 3,4 and 5 as 1 . This division is based on the expectation that different social organization should be associated with different potential for female monopolization, which should be connected with the strength of major selective pressure for male body size enlargement. And just the social grades 1-2 and 3-5 differ in the presence of the stable association of males with females. 
Because sample size was small for some species, we repeated all analyses after exclusion of species with the sample size in CBL less than 5 for a minority sex.

We used an $\alpha$ level of significance of 0.05 .

All analyses were performed in Statistica 10.0 (Stat Soft 2011), the PDAP:PDTREE module [71] within Mesquite 2.75 [72] and Compare vers. 4.6b [73] for independent contrasts and BayesTraits [74] for PGLS models.

Ethical note: The study is based on measurements of museum specimens and does not involve living animals.

\section{Additional file}

Additional file 1: The composite tree of ground squirrels used for the phylogenetic comparative part of the study.

\section{Competing interests}

The authors declare that they have no competing interests.

\section{Authors' contributions}

JM and LK conceived of, designed and coordinated the study and drafted the manuscript. JM collected the data and LK performed the statistical analyses. Both authors read and approved the final manuscript.

\section{Acknowledgement}

We are grateful to Linda K. Gordon (National Museum of Natural History, Smithsonian Institution, Washington D.C.), Galina I. Barnova (Zoological Institute of the Russian Academy of Sciences, St. Petersburg), Eileen Westwig (American Museum of Natural History, New York), Barbara Herzig (Museum of Natural History, Vienna), Brandy Jacobsen (Museum of the North, University of Alaska, Fairbanks), Rex Kenner (Cowan Vertebrate Museum, University of British Columbia, Vancouver), Gavin Hanke (Royal British Columbia Museum, Victoria) and Miloš Anděra (National Museum, Prague) for kind help in access to the material. JM thanks to Brian K. Schmidt and Christina A. Gebhard for their hospitality during his stay in Washington D.C. We thank Vladimír Vohralík and Andrey V. Tchabovsky for consultations of species sociality and Vladimír Vohralík, Věra Pavelková-Řićánková and two anonymous reviewers for comments on earlier drafts of the manuscript. JM was supported by the Ministry of Environment of the Czech Republic (project No. SP/2d4/61/08), LK by the Czech Science Foundation (No. 206/09/0895).

\section{Author details}

'Departments of Zoology and Ecology, Faculty of Science, Charles University in Prague, Viničná 7128 44, Praha 2, Czech Republic. ${ }^{2}$ Karlovy Vary Museum, Pod Jelením skokem 30, 360 01, Karlovy Vary, Czech Republic.

Received: 11 March 2012 Accepted: 7 May 2013

Published: 14 May 2013

\section{References}

1. Darwin CR: The descent of man and selection in relation to sex. London: John Murray; 1871

2. Fairbairn DJ, Blanckenhorn WU, Szekely T: Sex, size, and gender roles: evolutionary studies of sexual size dimorphism. Oxford: Oxford University Press; 2007.

3. Lindenfors $P$, Gittelman JL, Jones KE: Sexual size dimorphism in mammals. In Sex, size, and gender roles: evolutionary studies of sexual size dimorphism. Edited by Fairbairn DJ, Blanckenhorn WU, Szekely T. Oxford: Oxford University Press; 2007:16-26.

4. Lindenfors $\mathrm{P}$, Tullberg BS: Phylogenetic analyses of primate size evolution: the consequences of sexual selection. Biol J Linn Soc 1998, 64:413-447.

5. Lindenfors P, Tullberg BS, Biuw M: Phylogenetic analyses of sexual selection and sexual size dimorphism in pinnipeds. Behav Ecol Sociobiol 2002, 52:188-193.

6. Pérez-Barbería FJ, Gordon IJ, Pagel M: The origins of sexual dimorphism in body size in ungulates. Evolution 2002, 56:1276-1285.
7. Rensch B: Die Abhängigkeit der relativen Sexualdifferenz von der Körpergrösse. Bonner Zool Beitr 1950, 1:58-69.

8. Fairbairn DJ: Allometry for sexual size dimorphism: pattern and process in the coevolution of body size in males and females. Annu Rev Ecol Syst 1997, 28:659-687.

9. Abouheif E, Fairbairn DJ: A comparative analysis of allometry for sexual size dimorphism: assessing Rensch's rule. Am Nat 1997, 149:340-362.

10. Starostová Z, Kubička L, Kratochvíl L: Macroevolutionary pattern of sexual size dimorphism in geckos corresponds to intraspecific temperature-induced variation. J Evol Biol 2010, 23:670-677.

11. Shulte-Hostedde Al: Sexual size dimorphism in Rodents. In Rodent societies: An ecological and evolutionary perspective. Edited by Wolff JO, Sherman PW. Chicago and London: The University of Chicago Press; 2007:115-128.

12. McKenna MC, Bell SK: Classification of mammals above the species level. New York: Columbia University Press; 1997.

13. Herron MD, Castoe TA, Parkinson CL: Sciurid phylogeny and the paraphyly of Holarctic ground squirrels (Spermophilus). Mol Phylogenet Evol 2004, 31:1015-1030

14. Fabre P-H, Hautier L, Dimitrov D, Douzery EJP: A glimpse on the pattern of rodent diversification: a phylogenetic approach. BMC Evol Biol 2012, 12:88. doi:10.1186/1471-2148-12-88.

15. Nowak RM: Walker's mammals of the world. Baltimore and London: The Johns Hopkins University Press; 1999.

16. Bibikow DI: Die Murmeltiere der Welt. Heidelberg: Spektrum Akademischer Verlag; 1996.

17. Armitage KB: Sociality as a life-history tactic of ground squirrels. Oecol 1981, 48:36-49.

18. Michener GR: Kin identification, matriarchies, and the evolution of sociality in ground-dwelling sciurids. In Advances in the Study of Mammalian Behavior. Edited by Eisenberg JF, Kleiman DG. Lawrence: American Society of Mammalogists; 1983:528-572 [Special Publication No. 7].

19. Best TL, Titus AS, Caesar K, Lewis CL: Ammospermophilus harrisii. Mamm Species 1990, 366:1-7.

20. Best TL, Caesar K, Titus AS, Lewis CL: Ammospermophilus insularis. Mamm Species 1990, 364:1-4.

21. Best TL, Lewis $\mathrm{CL}$, Caesar K, Titus AS: Ammospermophilus interpres. Mamm Species 1990, 365:1-6.

22. Belk MC, Smith DH: Ammospermophilus leucurus. Mamm Species 1991, 368:1-8

23. Helgen KM, Cole RF, Helgen LE, Wilson DE: Generic revision in the holoarctic ground squirrels genus Spermophilus. J Mamm 2009, 90:270-305.

24. Ceballos G, Wilson DE: Cynomys mexicanus. Mamm Species 1985, 248:1-3.

25. Linzey AV, Rosmarino N, Willson K, Roth E, Hammerson G, Cannings S: Cynomys parvidens. In IUCN Red List of Threatened Species. Version 2010.4. IUCN; 2010 [www.iucnredlist.org].

26. Blumstein DT, Armitage KB: Does sociality drive the evolution of communicative complexity? A comparative test with ground-dwelling sciurid alarm calls. Am Nat 1997, 150:179-200.

27. Allainé D: Sociality, mating system and reproductive skew in marmots: evidence and hypotheses. Behav Process 2000, 51:21-34.

28. Oaks E, Young PJ, Kirkland GL, Schmidt DF: Spermophilus variegatus. Mamm Species 1987, 272:1-8

29. Popov VS: Rol' social'nyh svjazej v prostranstvennoj strukture poselenija zheltogo suslika. [The role of social relationships in the spatial structure of the colony in the yellow ground squirrel (Spermophilus fulvus Licht. 1823)]. PhD thesis. Moscow State University; 2007.

30. Kucheruk W, Khlyap LA: Lagomorphs and Rodents of Middle Asia (Zairseobraznye I Gryzuny Sredney Azii). Moscow: Geos; 2005.

31. Soldatova AN: Vlijanie plotnosti naselenia na charakter ispolzovanija territorii malym suslikom [Effect of population density on the character of the utilization of home ranges by Citellus pygmaeus Pall.]. Zool Zh 1962, 41:913-921.

32. Kryštufek B, Vohralík V: Mammals of Turkey and Cyprus, Vol. 2, Rodentia I: Sciuridae, Dipodidae, Gliridae, Arvicolinae. Koper: Science and Research Centre of the Republic of Slovenia; 2005.

33. Gür MK, Gür H: Spermophilus xanthoprymnus. Mamm Species 1995, 864:183-194. 34. Best TL: Spermophilus mohavensis. Mamm Species 1995, 509:1-7.

35. Webb TJ, Freckleton RP: Only half right: species with female-biased sexual size dimorphism consistently break Rensch's rule. PLoS One 2007, 2:e897.

36. Tubaro PL, Bertelli S: Female-biased sexual size dimorphism in tinamous: a comparative test fails to support Rensch's rule. Biol J Linn Soc 2003, 80:519-527. 
37. Stuart-Fox D: A test of Rensch's rule in dwarf chameleons (Bradypodion spp.), a group with female-biased sexual size dimorphism. Evol Ecol 2009, 23:425-433.

38. Reiss MJ: Sexual dimorphism in body size: Are larger species more dimorphic? J Theor Biol 1986, 121:163-172.

39. Székely T, Lislevand T, Figuerola J: Sexual size dimorphism in birds. In Sex, size and gender roles. Edited by Fairbairn D, Székely T, Blackenhorn W. Oxford: Oxford University Press; 2007:27-37.

40. Lacey EA, Wieczorek JR: Territoriality and male reproductive success in arctic ground squirrels. Behav Ecol 2001, 12:626-632.

41. Hoogland JL: Sexual dimorphism of prairie dogs. J Mamm 2003, 84:1254-1266

42. Schwagmeyer PL: Scramble-competition polygyny in an asocial mammal: Male mobility and mating success. Am Nat 1988, 131:885-892.

43. Polák J, Frynta D: Sexual size dimorphism in domestic goats, sheep, and their wild relatives. Biol J Linn Soc 2009, 98:872-883.

44. Frynta D, Baudyšová J, Hradcová P, Faltusová K, Kratochvíl L: Allometry of sexual size dimorphism in domestic dog. PLoS One 2012, 7:e46125.

45. Maynard-Smith J: The evolution of sex. Cambridge: Cambridge University Press; 1978.

46. Lande R: Sexual dimorphism, sexual selection, and adaptation in polygenic characters. Evolution 1980, 34:292-305.

47. Dobson FS, Michener GR: Maternal traits and reproduction in Richardson's ground squirrels. Ecology 1995, 76:851-862.

48. Huber S, Millesi E, Walzl M, Dittami J, Arnold W: Reproductive effort and costs of reproduction in female European ground squirrels. Oecologia 1999, 121:19-24.

49. Sauer JR, Slade NA: Uinta ground squirrel demography: is body mass a better categorical variable than age? Ecology 1987, 68:642-650.

50. Barash D: Marmots: Social behavior and ecology. Stanford: Stanford University Press; 1989.

51. Hoogland JL: Cynomys ludovicianus. Mamm Species 1996, 535:1-10.

52. Hayssen $V$ : Patterns of body and tail length and body mass in Sciuridae. $J$ Mamm 2008, 89:852-873.

53. Thorington RW Jr, Koprowski JL, Steele MA, Whatton JF: Squirrels of the World. Baltimore: The John Hopkins University Press; 2012.

54. Gür H: Why do Anatolian ground squirrels exhibit a Bergmannian size pattern? A phylogenetic comparative analysis of geographic variation in body size. Biol J Linn Soc 2010, 100:695-710.

55. Millesi E, Strijkstra AM, Hoffmann IE, Ditami JP, Daan S: Sex and age differences in mass, morphology, and annual cycle in European ground squirrels, Spermophilus citellus. J Mamm 1999, 80:218-231.

56. Zimmerman EG: Growth and age determination in the thirteen-lined ground squirrel, Spermophilus tridecemlineatus. Am Midl Nat 1972, 87:314-325

57. Turner BN, Iverson SL, Severson KL: Postnatal growth and development of captive franklin's ground squirrels (Spermophilus franklinii). Am midl nat 1976, 95:93-102.

58. Kratochvíl L, Fokt M, Rehák I, Frynta D: Misinterpretation of character scaling: A tale of sexual dimorphism in body shape of common lizards. Can J Zool 2003, 81:1112-1117.

59. Waterman JM: Male mating strategies in rodents. In Rodent Societes: an ecological and evolutionary perspective. Edited by Wolff JO, Sherman PW. Chicago and London: The University of Chicago Press; 2007:27-41.

60. Rowell TE: Beyond the one-male group. Behaviour 1988, 104:189-201.

61. Martins EP, Hansen TF: Phylogenies and the comparative method: A general approach to incorporating phylogenetic information into analysis of interspecific data. Am Nat 1997, 149:646-667.

62. Felsenstein J: Phylogenies and the comparative method. Am Nat 1985, 125:1-15.

63. Pagel MD: Modelling the evolution of continuously varying characters on phylogenetic trees. In Morphology, shape and phylogeny. Edited by MacLeod N, Foley PL. London: Taylor \& Francis; 2002:269-286.

64. Best TL, Titus AS, Lewis $\mathrm{CL}$, Caesar K: Ammospermophilus nelsoni. Mamm Species 1990, 367:1-7.

65. Díaz-Uriarte R, Garland T: Effects of branch length errors on the performance of phylogenetically independent contrasts. Syst Bio/ 1998, 47:654-672.

66. Díaz-Uriarte R, Garland T: Testing hypotheses of correlated evolution using phylogenetically independent contrasts: Sensitivity to deviations from Brownian motion. Syst Biol 1996, 45:27-47.

67. Revell $L$ : Phylogenetic signal and linear regression on species data. Meth Ecol Evol 2010, 1:319-329.
68. Capellini I, Venditti C, Barton RA: Phylogeny and metabolic scaling in mammals. Ecology 2010, 91:2783-2793.

69. Capellini I, Venditti C, Barton RA: Placentation and maternal investment in mammals. Am Nat 2011, 177:86-98.

70. Matthews LJ, Amold C, Machanda Z, Nunn CL: Primate extinction risk and historical patterns of speciation and extinction in relation to body mass. Proc R Soc B 2011, 278:1256-1263.

71. Midford PET, Garland T, Maddison WP: PDAP Package of Mesquite. Version 1.07. [http://mesquiteproject.org].

72. Maddison WP, Maddison DR: Mesquite: a modular system for evolutionary analysis. Version 2.75. [http://mesquiteproject.org].

73. Martins EP: COMPARE, Computer programs for the statistical analysis of comparative data. version 4.6b. [http://compare.bio.indiana.edu/].

74. Pagel M, Meade A: BayesTraits version 1.0 computer package. [www.evolution. rdg.ac.uk].

doi:10.1186/1742-9994-10-27

Cite this article as: Matějů and Kratochvíl: Sexual size dimorphism in ground squirrels (Rodentia: Sciuridae: Marmotini) does not correlate with body size and sociality. Frontiers in Zoology 2013 10:27.

\section{Submit your next manuscript to BioMed Central and take full advantage of:}

- Convenient online submission

- Thorough peer review

- No space constraints or color figure charges

- Immediate publication on acceptance

- Inclusion in PubMed, CAS, Scopus and Google Scholar

- Research which is freely available for redistribution

Submit your manuscript at www.biomedcentral.com/submit
C Biomed Central 